\title{
LA CONCIENCIA MORAL DESDE UNA PERSPECTIVA NEUROÉTICA. DE DARWIN A KANT ${ }^{1}$
}

\author{
ADELA CORTINA \\ Universidad de Valencia
}

\begin{abstract}
RESUMEN: La conciencia moral personal es una de las claves de bóveda de la vida moral. Darwin llega a afirmar que constituye la diferencia más importante entre el hombre y los animales inferiores. $Y$, sin embargo, las propuestas filosóficas más relevantes de nuestro tiempo (Rawls, Habermas) no se ocupan de ella expresamente, tal vez porque, como decía Aranguren, han primado la ética intersubjetiva sobre la intrasubjetiva. Pero sin reconstruir esa ética intrasubjetiva, se diluye la vida moral, tanto personal como social. En este trabajo intentamos dilucidar en qué consiste la conciencia moral personal, cuáles son sus bases neurobiológicas, y si bastan para explicar su lugar indeclinable en la vida moral. Para responder habremos de transitar de Darwin a Kant.
\end{abstract}

PALABRAS CLAVE: conciencia moral, ética, Churchland, Darwin, Kant, bases neuroquímicas, sentido moral.

\section{The moral conscience from a neuroethcal Standpoint. From Darwin to Kant}

ABSTRACT: The personal moral conscience is one of the keystones of moral life. Darwin went as far as to claim that this constitutes the most important difference between man and the lower animals. Yet the most relevant philosophical proposals of our times (Rawls, Habermas) do not expressly deal with this, perhaps because, as Aranguren said, they gave priority to intersubjective ethics over intrasubjective ethics. Without reconstructing that intrasubjective ethics, however, both personal and social life is watered down. In this work an attempt is made to explain what personal moral conscience consists of, what its neurobiological foundations are, and whether these are enough to explain its irreplaceable role in moral life. To answer these questions we will have to go from Darwin to Kant.

KEY WORDS: moral conscience, ethics, Churchland, Darwin, Kant, neurochemical foundations, moral sense.

\section{UNA PERSPECTIVA NEUROÉTICA}

La neuroética nace oficialmente como un saber específico a comienzos del siglo XXI, concretamente en mayo de 2002 (Marcus, 2002). Desde el comienzo van distinguiéndose en ella dos niveles, estrechamente vinculados entre sí, pero discernibles: la ética de las neurociencias, que intenta analizar la corrección o incorrección ética de las investigaciones neurocientíficas y de su aplicación,

1 Este estudio se inserta en el Proyecto de Investigación Científica y Desarrollo Tecnológico FFI2013-47136-C2-1-P, financiado por el Ministerio de Economía y Competitividad, y en las actividades del grupo de investigación de excelencia PROMETEO/2009/085 de la Generalitat Valenciana. 
contando con las teorías éticas ya existentes, y la neurociencia de la ética, que se propone descubrir las bases cerebrales de la conducta moral (Roskies, 2002; Levy, 2007). Mientras que la primera puede considerarse como una ética aplicada, como una rama de la bioética, la segunda se configura, a mi juicio, como ética fundamental y aborda cuestiones que han preocupado históricamente, y preocupan actualmente, a la filosofía, como es el caso de la aporía libertaddeterminismo, la existencia del yo o la relación mente-cuerpo, entre muchas otras cuestiones (Cortina, 2011a, 2011b, 2012; Pallarés, 2013; Amor, 2015)². Las investigaciones de este segundo modo de entender la neuroética tienen la peculiaridad de que permiten adentrarse en problemas tradicionales de la filosofía moral y contemplarlos a una luz nueva, e incluso extender sus reflexiones al conjunto de la filosofía práctica, configurando una neurofilosofía práctica, que podría diseñar los trazos de una nueva racionalidad práctica, teniendo en cuenta lo que sabemos acerca del cerebro (Cortina, 2012). Uno de esos problemas, central en la filosofía práctica, es el de la existencia y naturaleza de la conciencia moral, tema de este trabajo, que se inserta, por tanto, en el ámbito de la neuroética entendida como neurociencia de la ética. ¿Por qué ocuparse de ella?

Ciertamente, en la bibliografía más relevante sobre el mundo moral en los últimos tiempos el tratamiento de la conciencia personal rara vez está presente. En el ámbito filosófico el estudio de la conciencia personal se diluye a menudo en el de una conciencia social, filogenéticamente considerada, y en los trabajos de neuroética apenas aparece. De hecho, en obras tan emblemáticas como Teoría de la Justicia o Liberalismo político de John Rawls la voz «conciencia» ni siquiera aparece en el índice de materias, el tratamiento habermasiano de la conciencia en Conciencia moral y acción comunicativa se refiere a la teoría de la evolución social, aunque tome el modelo ontogenético de Kohlberg; y en lo que hace a los trabajos de neuroética, su presencia es tan escasa que The Oxford Handbook of Neuroethics, editado por Illes y Sahakian en 2011, ni siquiera recoge el tema. Y, sin embargo, la conciencia moral personal es una de las claves de bóveda de la vida moral, tanto de la vida personal como de la social. En lo que se refiere a la vida social, la conciencia moral es indispensable en las sociedades modernas, en las que se reconocen la libertad de conciencia, la objeción de conciencia, las cláusulas de conciencia, la desobediencia civil, que, aunque difiere de la objeción de conciencia, no puede prescindir de la conciencia moral (García-Marzá, 1998). Y en lo que se refiere a la conciencia personal, sin conciencia de autoobligación, que supone responsabilidad, se diluye la vida moral. En este trabajo queremos preguntarnos en qué consiste la conciencia moral personal, cuáles son sus bases neurobiológicas, y si bastan para explicar su lugar indeclinable en la vida moral personal.

Para responder a estas preguntas recurriremos a la neuroética, entendida como un saber intrínsecamente interdisciplinar, que cuenta con las aportaciones de la filosofía moral, de las neurociencias, con la genética, la economía

2 Enrique Bonete, por su parte, prefiere hablar de «Neuroética práctica» (BonETE, 2010). 
experimental, la antropología, la biología y la psicología evolutivas (Churchland, 2011, 3; Suhler and Churchland, 2011, 33). Los datos de los estudios neurocientíficos son sin duda relevantes, pero tienen que verse complementados con los datos de las disciplinas citadas, porque el estudio de los casos patológicos y las técnicas de neuroimagen, con ser muy valiosos, resultan insuficientes para llegar a resultados adecuadamente interpretables. Estas técnicas, como es sabido, han supuesto un gran avance en el ámbito de la neurociencias, pero a la vez presentan grandes dificultades, porque no representan «fotografías» del cerebro, como podría entenderse equivocadamente, sino que requieren una buena dosis de interpretación, también resulta difícil precisar en qué consiste el término "correlato» cuando se dice que existe correlación entre una determinada conducta y la activación de redes cerebrales, y, por otra parte, esa activación se produce con distintas conductas. (Lavazza \& Caro, 2010; Haynes, 2011). Contar con estudios interdisciplinares es, pues, esencial.

Esa es la razón por la que la neuroética aborda problemas nucleares de la filosofía y de la humanidad desde esa riqueza de aportaciones, como es el caso de la naturaleza de la conciencia moral. La cuestión pertenece al número de las que son urgentes e importantes, hasta el punto de que autores como Darwin consideran que es la que marca la mayor diferencia entre el hombre y el animal.

\section{LA DIFERENCIA MÁS IMPORTANTE ENTRE EL HOMBRE Y EL ANIMAL}

El estudio de la conciencia moral tiene una larga historia, cuyo comienzo en el mundo filosófico occidental suele situarse en Sócrates ${ }^{3}$. Podría parecer entonces que se preocupan por ella fundamentalmente autores no-naturalistas, es decir, autores que tratan de ir con su reflexión más allá de la experiencia sensible y de acceder a un ámbito abstracto, en que se descubren conceptos y valores universales alejados del mundo biológico ${ }^{4}$. Sin embargo, no es así, y, como muestra, podemos empezar este artículo con el texto de un autor declaradamente naturalista, Charles Darwin, quien afirma taxativamente en El origen del hombre:

«Suscribo totalmente la opinión de aquellos autores que sostienen que de entre todas las diferencias entre el hombre y los animales inferiores, el sentido moral o conciencia es, con mucho, el más importante. Este sentido,

\footnotetext{
3 Para un recorrido histórico sobre la noción de conciencia ver GómEz, 1998; HiLl Jr., 1998; OJaKangas, 2013. Con una especial atención a Zubiri, Conill, 2009.

4 Podemos entender el naturalismo como «la posición que sostiene que la naturaleza -entendida como el universo físico - es todo lo que hay; en segundo lugar, que las únicas verdades básicas son las verdades de la naturaleza; y, en tercer lugar, que el único conocimiento sustantivo es el de los hechos naturales». (AUdI, 2015, 28). Para la disputa sobre el naturalismo ético ver, entre otros, Nuccetelli and Shea, 2012; Joyce, 2014; Kitcher, 2014; ORTEGa, 2016.
} 
tal como señala Mackintosh, "tiene una supremacía legítima sobre cualquier otro principio de acción humana” $(2009,125)$.

La conciencia moral no es, pues, según Darwin, una dimensión intrascendente de la vida humana, sino que, a su juicio, marca la diferencia más relevante entre el hombre y el animal y tiene supremacía sobre cualquier otro principio humano; y en ello insiste reiteradamente a lo largo de su obra. Ciertamente, entre ciertos animales no humanos, como los chimpancés, y los seres humanos existen un conjunto de disposiciones comunes que podríamos llamar «protomorales» o, por decirlo con De Waal, los «building blocks» de la moralidad, entre los que señala la reciprocidad, el consuelo, la aversión a la inequidad, la empatía y el seguimiento de reglas de conducta reforzado por otros ${ }^{5}$. En algunos casos es discutible que también los animales estén dotados de esos «building blocks», pero, aunque así fuera, lo cierto es que no les capacitan todavía para desarrollar el sentido moral o conciencia, sino que hace falta algo más. ¿En qué consiste esta dimensión? Según Darwin,

«En último término, nuestro sentido moral o nuestra conciencia se convierte en un sentimiento muy complejo: se origina en los instintos sociales, es conducido en gran parte por la aprobación de nuestros semejantes, regido por la razón, el interés propio y, en los últimos tiempos, por sentimientos religiosos profundos, y confirmado por la instrucción y el hábito» $(2009,171)$.

El origen de la conciencia moral lo constituyen, pues, los instintos sociales de los seres humanos; y es un entramado de condiciones (aprobación, razón, autointerés, instrucción, hábito y sentimientos religiosos), de que carece el animal no humano, el que le permite constituirse ${ }^{6}$. Ciertamente, la afirmación del origen social de la conciencia es ya un lugar común a la hora de explicar su procedencia biológica (Salles y Evers, 2014). Y ésta es tal vez la razón de que en ocasiones se difumine su carácter personal y se llegue a identificar «moral» con «social».

Por eso, antes de entrar en ese origen es preciso aclarar qué entenderemos por «moral» y qué por «conciencia moral» para saber qué estamos buscando en la experiencia; es decir, aprender del Kant crítico que cualquier investigación empieza planteando a la naturaleza preguntas desde nuestros conceptos construidos y obligándole a respondernos. Pero también es preciso marcar una diferencia clara en relación con Kant: para diseñar ese concepto contamos con la experiencia adquirida a lo largo de nuestra historia biosocial y cultural. El marco interpretativo al que recurrimos no surge de las constataciones empíricas, sino de esa historia natural y social a lo largo de la cual hemos ido forjando nuestros conceptos: no de una razón empírica, pero tampoco de una razón pura, sino de una razón impura (Conill, 2006).

Como es sabido, los términos «moral»y «ética» se refieren a las costumbres y usos de los pueblos, pero también a la forja del carácter de las personas y

5 Franz B. M. De WaAl, 1992, 2006.

6 Ver Richart, 2016. 
al lugar donde se habita (Aranguren, 1994). Y en este elemental sentido etimológico es en el que resulta inadmisible que especialistas en neurociencias como Moll en algunos de sus escritos dibujen una imagen falsa de lo que las teorías filosóficas han dicho sobre la moralidad. Según él, durante siglos las teorías filosóficas han adoptado un acercamiento verbal lógico-deductivo a la moralidad, que trata de identificar principios universales que deberían guiar la conducta, unos principios que serían absolutos. Hoy, por el contrario, según Moll, ha nacido una nueva forma de abordar la moralidad, porque la neurociencia moral cognitiva se aproxima a ella a través de cambios de conducta moral en pacientes con disfunción cerebral, que proporcionan inferencias que conciernen a las dimensiones principales de la cognición moral. La neurociencia moral cognitiva pretendería elucidar los mecanismos neurales cognitivos que subyacen a la conducta moral, entendiendo por «moralidad» los conjuntos de costumbres y valores que adopta un grupo cultural para guiar la conducta social, una perspectiva que no asumiría la existencia de valores morales absolutos (Moll, 2005, 799). Ante afirmaciones como éstas sería de agradecer que quienes trabajan en neuroética y no son filósofos se cuidaran de hacer generalizaciones tan erróneas en relación con la tarea que han llevado a cabo las teorías filosóficas. En realidad, las más relevantes recurren a valores y principios universales, pero no absolutos, como es el caso de las que se sitúan en el nivel postconvencional en el desarrollo de la conciencia moral, con lo cual la crítica no da en ningún blanco.

En este sentido es más interesante la caracterización de moralidad que Moll hizo algunos años antes y repite más tarde, una caracterización que es usual en el ámbito de las ciencias sociales. Siendo especialista en el tema de las emociones morales, entiende que estas emociones «están estrechamente ligadas a los intereses o al bienestar o bien de la sociedad como un todo o bien de personas distintas al agente»(Moll, 2002, 2730; 2005, 807). Esta tendencia a vincular la moralidad con las conductas que reprimen el egoísmo y potencian la solidaridad es muy usual, y queda bien expresada, a mi juicio, en la conocida caracterización de Durkheim, a la que recurre en algún momento Haidt: «es moral todo lo que es fuente de solidaridad, lo que fuerza al hombre (...) a regular sus acciones por otra cosa (...) que su egoísmo» (Haidt, 2012, 220). El propio Haidt la asume y amplía esta concepción de lo moral, diciendo que «los sistemas morales son conjuntos engranados de valores, virtudes, normas, prácticas, identidades, instituciones, tecnologías y mecanismos psicológicos evolucionados, que trabajan conjuntamente para suprimir o regular el autointerés y hacer sociedades lo más cooperativas posible» (ibid.).

La moralidad consistiría entonces en el conjunto de valores, principios y costumbres que llevan a controlar el egoísmo y reforzar la cooperación y la solidaridad, en principio entre los seres humanos próximos, paulatinamente también en el conjunto de la humanidad. El mensaje que se extraería sería el siguiente: la convivencia entre seres radicalmente egoístas sería inviable y por eso la moralidad es un producto de las presiones de la evolución, que han conformado mecanismos sociales cognitivos y emocionales, ya presentes en 
nuestros antecesores, hasta llegar a formas humanas de experiencia. La evolución de la corteza prefrontal estaría íntimamente relacionada con la emergencia de la moralidad. ¿Cómo se produjo esta evolución?

\section{El ORIGEN EVOlUtivo DE LA CONCIENCIA MORAL}

Desde un punto de vista evolutivo, la aparición de la conciencia moral parece ligada a lo que se ha llamado «el misterio del altruismo biológico» ${ }^{7}$. En efecto, resolver lo que más tarde se llamó «la paradoja del altruismo» es una de las dificultades con las que se encontró Darwin y que pudo llevarle a retrasar la publicación de El origen del hombre (Cela y Ayala, 2001, cap. 11). ¿Cómo se explica desde la hipótesis de la selección natural que no desaparezcan los altruistas? Darwin adujo como posible causa la selección de grupos: la conducta altruista no proporcionaría ventajas a los individuos dentro de un grupo, pero sí permitiría la selección entre los grupos, porque los grupos internamente solidarios resistirían más en la lucha por la supervivencia ${ }^{8}$. Una hipótesis muy sugestiva que, sin embargo, deja sin explicar el altruismo individual, porque en los grupos abundan los polizones dispuestos a viajar a costa de los demás, calculando cómo hacerlo para no salir perjudicados. ¿Cómo se explica entonces el altruismo individual? En la respuesta a esta pregunta tiene un lugar importante la aparición de la conciencia moral.

La respuesta más convincente es que a lo largo de la evolución los grupos se protegen castigando a los polizones de diversas formas: eliminándolos físicamente, condenándoles al ostracismo, o haciéndoles sufrir la vergüenza de privarles de su reputación ${ }^{9}$. Por eso los polizones quedan arrumbados y tienen pocas opciones de reproducirse, mientras que los altruistas son más apreciados por la colectividad y tienen mayores posibilidades de reproducción. Pero para que este mecanismo funcionara se hizo necesario que los individuos adquirieran un conjunto de capacidades, que han sido decisivas para componer la biología de la conciencia moral.

7 Para una recopilación de interpretaciones de la conciencia desde una perspectiva evolucionista ver F. B. M. De Waal, P. S. Churchland, T. Pievani \& S. Parmigiani (eds.), 2014.

8 «En el caso de los seres humanos, el egoísmo, la experiencia y la imitación se añaden seguramente a la capacidad de simpatía, como ha demostrado míster Bain; porque nos impulsa la esperanza de recibir el bien a cambio de realizar actos de amabilidad compasiva hacia los demás, y la compasión se ve muy reforzada por la costumbre. Por compleja que sea la manera en que este sentimiento se pueda haber originado, puesto que es de gran importancia para todos aquellos animales que se ayudan y se defienden mutuamente, tuvo que verse aumentado mediante selección natural; porque aquellas comunidades que incluían el mayor número de miembros más compasivos prosperaron más, y produjeron el mayor número de descendientes» (DARWIN, 2009, 137 y 138).

9 Ya en 1971 R. L. Trivers identificó la «agresión moralista» como una fuerza selectiva en el incumplimiento de normas de los cazadores-recolectores (TRIVERS, 1971). 
Esas capacidades serían la conciencia de que existen las leyes del grupo, de que violarlas va a reportar castigos físicos o espirituales, y, en cualquier caso, el desprecio de los compañeros, y muy especialmente, el sentimiento de vergüenza que se experimenta al perder la reputación en el seno del grupo, siendo así que la reputación es esencial para sobrevivir. Sentimiento de vergüenza y afán de reputación serían indispensables para la supervivencia, no sólo de los grupos, sino también de los individuos, y con su aparición se daría el paso esencial en la evolución moral humana.

En relación con este punto la hipótesis del chismorreo cobra cada vez más fuerza. Supuestamente, los individuos de las tribus de cazadores-recolectores murmuraban y criticaban a los violadores de las reglas del grupo. Por su parte, los miembros del grupo se comportaban de forma altruista para mantener la reputación. Según estas versiones, la preocupación por la alabanza y el reproche de los demás es el estímulo más importante para desarrollar las virtudes sociales, anclado en el sentimiento de simpatía (Darwin, 2009, 137). Pero si así han sido las cosas, llevaba razón Hume al asegurar en su estudio de la naturaleza humana que el orgullo y el sentimiento de inferioridad son pasiones naturales y originales de los hombres, ligadas al sentimiento de simpatía (Hume, II, 472).

Para lo que aquí nos ocupa, desde un punto de vista evolutivo, parecen destacarse al menos dos caracterizaciones de la conciencia moral. Según una de ellas, puede entenderse como una voz estratégica que nos aconseja cómo alcanzar nuestros intereses de forma prudente, sin soliviantar al grupo que puede castigarnos. El ser humano es egoísta y para alcanzar sus objetivos tiene que calcular hasta dónde puede llegar sin perder su reputación y sus bienes. Porque, a fin de cuentas, como diría Nietzsche, «nos las arreglamos mejor con nuestra mala conciencia (Gewissen) que con nuestra mala reputación $(R u f) »^{10}$. Siguiendo esta línea estratégica entenderá Alexander que la conciencia moral es «la pequeña voz silenciosa que nos dice hasta dónde podemos llegar persiguiendo nuestros intereses sin correr riesgos intolerables» $(1974,102)$.

Sin embargo, también es posible entender con Boehm, entre otros, que «tener conciencia es identificarse con los valores de la comunidad, lo cual significa identificarse con las reglas del grupo. Hay que conectar con esas reglas emocionalmente, sentirse orgulloso cuando se cumplen y avergonzado cuando no» (BOHEM, 2012, 113). En este sentido insistirá también Churchland: durante el proceso de socialización el niño va aprendiendo que determinadas conductas reciben la aprobación de su grupo social, mientras que otras reciben el rechazo. Como la aprobación le produce placer y el rechazo, dolor, es este sistema de recompensas el que le lleva a evaluar el primer tipo de conductas como buenas y el segundo como malas. El clan va instilando esta educación a través del chismorreo, y también proponiendo modelos de conducta, contando

10 «Man wird mit seinem schlechten Gewissen leichter fertig als mit seinem schlechten Rufe» (NieTzsche, 1999, parágrafo 52, p. 416). 
fábulas y a través de canciones. Y el niño va adjudicando una valencia emocional a las distintas formas de actuar, según la aprobación o el rechazo que puede anticipar, de modo que va generando sentimientos de que algo es bueno o malo $\tan$ fuertes que puede creer que valen objetiva y universalmente, e incluso que tienen un origen divino.

Esta historia es, evidentemente, especulativa, y resulta muy sugerente, pero deja sin explicar aspectos muy importantes de la vida humana:

1) La contradicción entre los dictados de la conciencia y las reglas de la sociedad, una contradicción de la que son figuras señeras Sócrates y Antígona, pero se multiplica a lo largo de la historia en los mártires, los objetores de conciencia, los desobedientes civiles, los resistentes. En ocasiones se oponen a las leyes de su sociedad por obedecer a la ley de Dios, en ocasiones por seguir lo que consideran la ley de la humanidad, en otras, por atender a su ley individual desde una ética de la autenticidad. Puede decirse que quien objeta frente a las leyes de su sociedad lo hace teniendo in mente las de otra sociedad — real o ideal- que es para él la referencia adecuada, pero en cualquier caso, la persona no se conforma con aceptar las leyes que le convendría acatar para sobrevivir en paz, sino que sacrifica su tranquilidad por normas que considera más humanas.

2) Pero tampoco puede explicar esta interpretación evolucionista de la conciencia moral la emergencia de creadores morales, de innovadores morales, que han lanzado propuestas superadoras, e incluso contrarias, a las leyes sociales. Son capaces de romper con las normas de la moral cerrada y abrir creativamente propuestas innovadoras con capacidad de arrastrar (Bergson, 1996). Buda o Jesús de Nazaret, por poner dos ejemplos, serían innovadores en este sentido, como de algún modo reconocería el propio Darwin en el segundo caso con las siguientes palabras:

«Hacer el bien a cambio del mal, amar a nuestro enemigo, es una cima de moralidad a la cual es dudoso que los instintos sociales nos hubieran conducido nunca por sí mismos. Es necesario que dichos instintos, junto con la simpatía, se hubieran cultivado y extendido mucho mediante el uso de la razón, la instrucción y el amor o el temor de Dios, antes de que se hubiera pensado en esta regla de oro y se la hubiera obedecido» (Darwin, 2009, nota 27, 145 y 146).

3) La moralidad suele vincularse con el tipo de costumbres y normas que exige superar el egoísmo y llevan a preocuparse por los demás seres humanos o por la colectividad, como dijimos anteriormente. Sin embargo, conviene recordar que existe un tipo de deberes, llamados tradicionalmente, «deberes para consigo mismo», que obligan al sujeto a respetarse también a sí mismo, y no sólo a preocuparse por los demás. La conciencia de estos deberes, que aparecen en los tratados tradicionales de moral, nace, según Darwin, con la civilización. Mientras que en las 
sociedades bárbaras los individuos no se preocupan de su autoimagen, en las sociedades civilizadas sí lo hacen ${ }^{11}$. En este punto se produce una de las conexiones entre Darwin y Kant, porque la conciencia moral tendrá una función de juez y porque los deberes consigo mismo son los que abren la consideración sobre los fines que son al mismo tiempo deberes.

Pero antes de pasar a considerar la función de juez de la conciencia moral desde la perspectiva kantiana, que Darwin, a su modo, comparte, sugeriremos las bases neuroquímicas de la conciencia moral.

\section{LAS BASES NEUROQUímicAS DE LA MORALIDAD}

En uno de los trabajos llevados a cabo con Suhler, Churchland plantea el asunto de las bases neurobiológicas de la moralidad en tres pasos que, a su juicio, van ganando en seguridad: psicología evolutiva, neuroeconomía y, por último, neuroendocrinología y neurobiología evolutiva (Suhler \& Churchland, 2011). En este último punto mantiene la hipótesis, que defendía también en Braintrust, de que la neuroquímica del vínculo (attachment) en los mamíferos es el elemento central explicativo de la moralidad, porque explica que un animal cuide de otros o exprese valores sociales $(2011,27)$. El punto de partida es la autopreservación: todo animal elige el cuidado de sí mismo frente al descuido de sí mismo, porque, en caso contrario, no puede transmitir sus genes, de suerte que el cuidado es una función básica de los sistemas nerviosos. Los valores más básicos son los de permanecer vivo y bien, pero los mamíferos extienden este autocuidado a las crías, y los seres humanos, a otras personas, sobre todo parientes y allegados. Es posible — añade Churchland- que este sentimiento esté a la base de lo que Hume entendía por «sentimiento moral» (Churchland, 2011, 210).

Parece que los pasos cruciales que llevan del autocuidado a cuidar también de otros dependen de los mecanismos neuronales y del cuerpo que «maternalizan» el cerebro de la hembra, que a su vez dependen de los neuropéptidos oxitocina y arginina vasopresina, junto con otras hormonas. Los mamíferos que más cuidaban a sus crías tuvieron más crías supervivientes que los que las descuidaban. Pero también esto pudo modificarse más adelante para apoyar el cuidado de otros, que no son crías, pero cuyo bienestar tiene consecuencias para el propio y el de la especie (Churchland, 2011, 31). Oxitocina y vasopresina se liberan en el hipotálamo y se extienden a otras áreas subcorticales, como las implicadas en la recompensa (incluido el núcleo accumbens), en la regulación de la conducta sexual y en la de tener hijos. La oxitocina es más abundante en

11 «Las otras virtudes denominadas de respeto hacia sí mismo, que no afectan de manera evidente (aunque pueden hacerlo realmente) al bienestar de la tribu, no han sido nunca estimadas por los salvajes, aunque ahora son muy apreciadas por las naciones civilizadas» (DARWIN, 2009, 153). 
las mujeres que en los varones, mientras que la vasopresina es más abundante en los varones.

Aunque la investigación está todavía en marcha, cuando esos dos péptidos se ligan a sus respectivos receptores, parece que la oxitocina se libera durante las interacciones sociales positivas e inhibe conductas defensivas. Administrada a los machos, incrementa la agresión frente a los intrusos y la disminuye hacia los cachorros. Junto a oxitocina y vasopresina, es importante la dopamina como expresión de la conducta social, es un neurotransmisor que juega papeles muy importantes, por ejemplo, en el aprendizaje, en el apareamiento y en la paternidad. Además de los cambios de la oxitocina también se modificó el sistema mamífero del afecto negativo (dolor, miedo, pánico, ansiedad), como advertencias en el tallo cerebral y el hipotálamo que incitan a protegerse. De todo ello se sigue que puesto que los seres humanos tienen cerebros sociales, nuestro sistema de dolor más generalizado nos hace sentir mal no sólo cuando nuestro bienestar se ve amenazado, sino cuando el bienestar de nuestros seres queridos también lo está $(2011,39)$. ¿En qué consiste en todo este entramado la conciencia?

Desde esta perspectiva —dirá Churchland—, la realidad neurobiológica de la conciencia consistiría en el dolor que experimentamos al ser rechazados, en el placer de pertenecer a un grupo y en la imitación de aquellos a los que admiramos $(2011,192)$. Las distintas áreas del cerebro habrían evolucionado para darnos nuestra facultad moral, que consistiría en el sentido de lo correcto y lo incorrecto, la capacidad de enrojecer y la vergüenza, el sentido de la empatía, el conocimiento de que se nos puede castigar, la conciencia de nuestra reputación, la conciencia de que podemos aprovecharnos de tener buena reputación y también la conciencia del límite en el que hay que detenerse. «Dadas las redes neuronales normales, el dolor de ser esquivado y el placer de pertenecer, junto con la imitación de aquellos a los que admiramos, da lugar a intuiciones poderosas sobre la absoluta corrección o incorrección de clases de conducta. Este esquema de respuestas, buena parte del cual toma forma durante las interacciones cerebro-genes-medio cuando el niño empieza su vida social, es la realidad biológica que hay tras nuestro hablar de conscience». Si se la interpretara como una entidad metafísica, separada de la neurobiología de la socialidad y el aprendizaje social, perdería todo enclave» $(2011,192-193)$.

Esta afirmación es, sin duda, innecesaria. Ninguna realidad humana está separada de la neurobiología de la socialidad y del aprendizaje social, tampoco la conciencia. Pero que esté ligada a ellos no significa que se reduzca a ellos. Por una parte, porque la conciencia, entendida como la voz estratégica de que habla Alexander, o como la identificación con las normas de la comunidad a la que aluden Boehm y tantos otros, y que se sustentaría en las bases neurobiológicas descritas, es excluyente: excluye las normas y principios que no acepta el grupo. Por eso Haidt reconoce que: «La oxitocina liga a la gente selectivamente a sus grupos, no a la humanidad. Las neuronas espejo ayudan a empatizar con otros, pero particularmente con los que comparten la misma matriz moral. Sería hermoso que los seres humanos estuviéramos diseñados 
para amar a todos incondicionalmente. Hermoso, pero improbable desde una perspectiva evolutiva. El amor parroquial, disparado por la competición con otros grupos y ampliado por la semejanza, un sentido del destino compartido y la supresión de los free riders, puede ser lo más que podemos conseguir» (2012, 201). Una conciencia moral, así entendida, sólo puede expresarse a través de imperativos hipotéticos de astucia (Klugheit), que aconsejan acoplarse a las normas del grupo. Como bien dice Haidt, que la entiende de este modo, la moralidad une a los cercanos, pero ciega en relación con los demás.

Por otra parte, la liberación de oxitocina al llevar a cabo conductas prosociales puede producir placer, pero también lo producen otras conductas, como la venganza o la victoria. Como apunta Evers, entre otros, nuestra identidad innata, basada neuralmente de forma especie-específica, nos dispone a desarrollar tendencias evaluativas universales como el autointerés, la disociación, la simpatía selectiva, la empatía y la xenofobia. Con lo cual, nuestra identidad neuronal como personas nos hace sociales, pero también individualistas y autoproyectivos (Evers, 2015, 2). A pesar de que tenemos una capacidad natural de empatía (capacidad de aprehender los estados mentales de otros), simpatía (capacidad de cuidar de otros) y asistencia mutua, el ser humano puede ser descrito también como autointeresado, y xenófobo (Evers, 2015, 5). No es extraño teniendo en cuenta la necesidad de cohesión con los cercanos y protección frente a los extraños que influyó poderosamente en la conformación del cerebro. Experimentamos placer al atender a nuestros sentimientos sociales, pero también a los que favorecen nuestro interés. ¿Es a esto a lo que se reduce la conciencia moral personal?

\section{CONCIENCIA MORAL Y SENTIDO MORAL. LA CONCIENCIA MORAL COMO JUEZ INTERIOR}

En su trabajo sobre «The origins of moral judgement», y justamente refiriéndose al texto de Darwin que hemos citado al comienzo de este artículo, afirma Joyce que parece obvio decir que «el sentido moral o conciencia» es una facultad que produce juicios morales. Darwin no se preguntaría si ser moralmente bueno es un producto de la evolución, sino si lo es la capacidad de hacer juicios morales dirigidos hacia sí mismo (Joyce, 2013, 262 y 263). Lo cual es cierto, pero también conviene recordar que Darwin distingue entre el sentido moral y la conciencia moral, lo cual es clave para lo que aquí nos importa. Ambos están estrechamente ligados entre sí, pero entre ellos existe una importante distinción: el sentido moral nos dice lo que debemos hacer, mientras que la conciencia nos reprueba internamente si lo desobedecemos, ejerce la función de un juez interior, de un inward monitor (Darwin, 2009, 150, 129). De donde se sigue que el sentido moral es el que nos capacita para formular juicios morales, juicios sobre lo moralmente bueno y malo, correcto o incorrecto, mientras que la función propia de la conciencia es la de juzgarnos a nosotros mismos, dirigir 
nuestro juicio hacia nosotros mismos; hace posible la autorreflexión y la formulación de juicios sobre sí mismo.

Ciertamente, como bien decía Aranguren, ya en el último tercio del siglo xx la ética intersubjetiva invadió el ámbito de la ética en su conjunto y expulsó de él lo que podría ser una ética intrasubjetiva, la ética del sujeto en relación consigo mismo (Aranguren, 1986). Y llevaba razón Aranguren, porque qué duda cabe de que nuestro conocimiento moral tiene como punto de partida la relación intersubjetiva de seres cuyos cerebros son sociales; de hecho, el factum de los actos de habla o de las acciones comunicativas, que acontece desde la infancia, es el que despierta en el niño el sentido de la responsabilidad y la libertad: el sentido de su agencia moral (Habermas, 2006, 178 y 179); pero precisamente por eso el niño descubre la capacidad de dialogar, no sólo con otros, sino también consigo mismo, la capacidad de exigirse a sí mismo actuar, no sólo atendiendo a las leyes del grupo, sino también a las que él considera justas. Desde la perspectiva del participante en el lenguaje, desde el ejercicio del diálogo intersubjetivo y desde el reconocimiento recíproco se llega también a la conciencia moral, en el sentido de Kant, como una voz interior que juzga y que el hombre no puede dejar de oír. Ésta es la tradición de Sócrates, la tradición que considera que la conciencia (synoida emautó) está relacionada con la acusación que el sujeto se dirige a sí mismo, y ésta es también la forma de entenderla de Darwin, como hemos expuesto.

Podríamos caracterizar esta noción de conciencia, siguiendo a Hill, como «una capacidad, atribuida comúnmente a la mayor parte de los seres humanos, para darse cuenta de que o discernir que lo que han hecho, están haciendo o están a punto de hacer (o no hacer) es incorrecto, está mal o es merecedor de desaprobación» (Hill, 1998, 14). Aunque la opinión pública influye en el desarrollo de la conciencia y puede influir indirectamente en sus contenidos, la conciencia es un modo de llegar a creencias morales relevantes sobre nuestros actos a través del instinto o juicio personal (Hill, 1998, 41). Esta noción de conciencia puede articularse de modos diversos, pero la kantiana añade el punto de la incondicionalidad: la conciencia no juzga sobre si la propia actuación ha sido adecuada para merecer la aceptación de la comunidad y, por lo tanto, no es una facultad estratégica, sino que pronuncia su sentencia poniendo al sujeto frente a sí mismo y haciéndole consciente de que es responsable de sus opciones y, por tanto, libre.

La fuerza de la conciencia moral es tal que en las Vorlesungen Kant no la considera como una facultad, sino como un instinto irresistible. La cuestión se plantea en el contexto de la imputación y, por lo tanto, de la atribución de responsabilidad de las acciones, y Kant se esfuerza por mostrar que la fragilidad de la naturaleza humana no puede ser una razón para que un sujeto intente disculpar internamente su mala actuación (1988, 107-109; 169-175). Es en este punto en el que aparecen la figura del juez interior y la distinción entre un foro externo, que es el foro humano, y el foro interno, que es el de la conciencia.

Desde esta perspectiva, las peculiaridades de la conciencia moral serían las siguientes: 1) aparece como un instinto, 2) se identifica con el foro interno, 3) el 
foro interno es el foro divino, a diferencia del foro externo, que es humano. En efecto, asegura Kant que en la naturaleza de los seres humanos encontramos un instinto (Instinkt, Instinctus), que caracteriza como «un impulso involuntario e irresistible, que nos coacciona a juzgar válidamente sobre nuestras acciones; se trata de un malestar interno acerca de las malas acciones y de un gozo interior respecto de las buenas, siempre que la acción se compadezca con la ley moral» $(1988,107)$. Esta doctrina de la conciencia moral como instinto de juzgar sobre la moralidad de nuestras acciones tendría su origen en el Gewissenstrieb de Crusius, que es «la voz de Dios a través de la naturaleza». Pero en el caso de Kant no deja de resultar desconcertante que, a pesar de que el hombre sea el sujeto agente de su vida, se encuentre con ese juez interior que aparece como algo dado e irresistible, como «algo que nos juzga en contra de nuestro arbitrio y es, por lo tanto, un auténtico juez» (1988, 108); no es una facultad libre, no elegimos ser jueces de nuestra conducta, la voz interior nos acusa a nuestro pesar y no podemos eludirla (Hill, 33).

A mi juicio, que la conciencia no sea una facultad libre sólo puede explicarse por una de estas tres razones: 1) o bien el juez interior es Dios, en la línea de Crusius, 2) o bien el acto de juzgar pertenece también a la estructura misma de la razón práctica, 3) o bien es un instinto heredado biológicamente, que de una manera oscura se vincula con la ley racional y conforma un punto de contacto entre la ley racional, inteligible, y el hombre sensible, siendo un vínculo entre libertad y naturaleza. Considero, con Heubült, que las tres formas coexisten en la idea kantiana de conciencia (Heubült, 1980). Pero lo bien cierto es que no se trata de una norma de prudencia que aconseja actuar sagazmente para mantener una buena reputación, porque el juicio prudencial no es el de la conciencia moral, sino el que procede de intereses patológicos, que aconsejan pragmáticamente otra forma de actuar. La conciencia moral, por el contrario, apunta a una ley incondicionada, inmanipulable, a diferencia del malestar interior que causa el incumplimiento de los consejos de la sagacidad.

Por otra parte, la conciencia moral es natural, y no revelada, como entendía Baumgarten. La razón de ello es clara: en caso contrario, quien no tuviera una conciencia cultivada a través de la educación, no tendría remordimientos. «La conciencia moral es, pues, única y exclusivamente natural» (Kant, 1988, 173-174). Evidentemente, se encuentra aquí presente la huella del pasaje de la Epístola de S. Pablo a los Romanos, referido a los preambula fidei, a esos umbrales de la fe que se encuentran en el corazón de todo hombre: «En efecto, cuando los gentiles que no tienen ley, cumplen naturalmente las prescripciones de la ley, sin tener ley, para sí mismos son ley; como quienes muestran tener la realidad de esa ley escrita en su corazón, atestiguándolo su conciencia con sus juicios contrapuestos, que les acusan y también les defienden ${ }^{12}$.

12 Epístola a los Romanos, 2, 14-15. En hebreo no hay palabra para "conciencia», aparece «syneidesis» en algunas ocasiones. En las Epístolas de S. Pablo «syneidesis» aparece 14 veces y en el total del Nuevo Testamento, 22 (OJaKangas, 2013, 70). 
Pero también podría ocurrir que, como hemos comentado, el cerebro humano se hubiera ido conformando al hilo de la evolución biológico-cultural de modo que el instinto o la disposición natural a dejarse juzgar hubiera quedado inscrita en él, y, en tal caso, dejaría de ser un misterio que un sujeto autónomo se viera forzado a juzgarse a sí mismo por «algo que nos juzga en contra de nuestro arbitrio y es, por lo tanto, un auténtico juez». En efecto, de entre las tres modulaciones de la conciencia que hemos apuntado, una de ellas, a mi juicio, aparece formulada anteriormente en La Metafísica de las costumbres, concretamente en las «Prenociones estéticas de la receptividad del ánimo para los conceptos del deber en general». Esas prenociones son de la mayor importancia, porque se refieren a disposiciones morales que, si no se tienen, tampoco hay un deber de adquirirlas (Kant, 1989, 253-259). Forman parte de la naturaleza humana y, aunque son estéticas, se les puede calificar a la vez de morales, porque preparan a la persona para escuchar la voz del deber, para entenderla y para poder obedecerla. Son - recordemos- el sentimiento moral, la conciencia moral, el amor al prójimo y el respeto por sí mismo (la autoestima). Constituyen una especie de antenas de la naturaleza, que permiten percibir el deber.

Podríamos decir que un ser que careciera de estas disposiciones no tendría la base natural indispensable para escuchar la voz de la ley moral y seguirla. Recurriendo a la distinción indispensable en el mundo filosófico entre base y fundamento, la ley moral sería el fundamento de la obligación moral, pero las disposiciones naturales estéticas serían la base sin la que resulta imposible escuchar la voz de la ley y seguirla. Se trataría, como dice Jesús Conill, de una «estética de la libertad» (2006, 41 ss.): es una predisposición del ánimo, estética, pero natural, que consiste en la razón práctica que muestra al hombre su deber en el caso concreto, absolviéndolo o condenándolo. De modo que forma parte de su naturaleza biológica moral la predisposición a juzgarse a sí mismo.

Justamente esta conciencia, como herencia biológica, podría ser el punto de contacto entre la naturaleza y la libertad, al igual que las otras tres prenociones estéticas. Hay sin duda una historia natural, en la que ya ha influido la cultura. Se trata de que la conciencia del deber sea a la vez el móvil de las acciones, y sólo puede serlo si el agente moral actúa con la certeza de haber intentado dar con el juicio justo, aunque el entendimiento pueda equivocarse al juzgar (Kant, 1989, 224; 1969, 181, 182). Heubült entiende, a mi juicio acertadamente, que tanto en 1787 como en 1797 la facultad del ánimo presupuesta por Kant como disposición (Anlage) moral (la facultad de la razón práctica) se expresa en dos funciones, ligadas entre sí: (1) como precepto (Weisung) moral a través de una razón legisladora, dirigida a un objeto del deber, y (2) como conciencia (Gewissen), a través de una coacción (Gewalt) que se dirige al sujeto, vigilando esa legislación práctica. Estas funciones aparecen como dos juicios morales: a través de la ley racional el hombre juzga sobre un objeto del deber como bueno o malo; en el tribunal de la conciencia juzga sobre el sujeto como culpable o inocente. A mi juicio, en el primer caso nos encontraríamos ante lo que Darwin entendía como sentido moral, en el segundo, ante la conciencia moral. 
Sin embargo, cabe preguntar si esas prenociones estéticas son, como tales, objeto de experiencia, o son más bien un presupuesto indispensable para poder reconocer que los seres humanos son agentes morales. En el primer caso estaríamos buscando un correlato neurobiológico del sujeto agente (Habermas, 2006, 184). En el segundo, se trataría de reconocer que la conciencia moral es, junto a la ley moral, la ratio cognoscendi de la libertad, y que la libertad es la ratio essendi de la ley moral y de la conciencia moral. En efecto, la conciencia moral aparece en la Crítica de la razón práctica como una facultad (Vermögen) que tiene el hombre de juzgar sobre sí mismo. Aparece en la «Aclaración crítica a la analítica de la razón pura práctica», es decir, ligada a la idea clave del conjunto de la obra, la idea de libertad. Ciertamente, Kant considera que la libertad no es objeto de demostración científica, pero, a la vez, que la razón, en su uso práctico, posee razones suficientes para postularla, al reconstruir las condiciones trascendentales que dan sentido y validez al obrar humano. Uno de esos hilos conductores es el hecho ineludible de que los hombres se imputen sus acciones a sí mismos y se sientan incómodos con sus malas actuaciones (Kant, 2000, 198 y 199). La conciencia moral aparece, pues, de nuevo ligada a la autoimputación de las acciones, que es posible por la libertad. La eleuteronomía toma el lugar de la eudaimonía como piedra angular del mundo moral (Kant, 1989, 227; Conill, 1991; 2006, parte I).

En la Doctrina de la Virtud distingue Kant entre los deberes que el hombre tiene hacia sí mismo y los que tiene hacia los demás, y empieza su análisis por los primeros. Ésta es una muestra bien expresiva, que el propio Kant confirmará, de que la clave de todo el edificio moral es la auto-obligación. El deber moral no consiste sólo en cumplir obligaciones con los demás, sino en primer lugar en cumplirlas consigo mismo, y en saberse obligado a cumplirlas con los demás desde esa auto-obligación. Aunque pueda parecer contradictorio, dirá abiertamente "yo no puedo reconocer que estoy obligado a otros más que en la medida en que me obligo a mí mismo: porque la ley en virtud de la cual yo me considero obligado, procede en todos los casos de mi propia razón práctica, por la que soy coaccionado, siendo a la vez el que me coacciono a mí mismo» (Kant, 1989, 275).

Podríamos decir que ésta sería la característica de la obligación moral, que trasciende las exigencias de cualquier otra forma de coacción social: biológicamente podemos estar predispuestos a cumplir las normas del grupo para evitar el reproche, el castigo y la pérdida de reputación, y es lo que nos aconseja nuestra razón prudencial, como razón de un vernünftiges Wesen, de un ser corporal dotado de razón prudencial (Kant, 1989, 276). Pero un ser racional, un Vernunftwesen, dotado de racionalidad práctica, es capaz de auto-obligación, y por eso existe un mundo moral específico que ordena incondicionadamente cultivar la propia conciencia para dar con la norma justa. Como bien dice Korsgaard, en su interpretación de Kant, nuestra capacidad para obligarnos a nosotros mismos es la fuente de la normatividad (1996, 91-102).

Ciertamente, en el siglo xxi la ética del discurso intenta reconstruir la propuesta kantiana desde una pragmática no empírica del lenguaje, que reconoce 
el carácter incondicionado de los afectados por un discurso práctico; pero, a mi juicio, también en la ética del discurso el criterio último es el del sujeto moral que se pregunta desde su conciencia si los acuerdos a los que llegan los interlocutores de un diálogo se obtienen en condiciones de racionalidad o en condiciones ideológicas. En este segundo caso, la norma todavía no podría tenerse por justa. Sin duda los contenidos de la conciencia del sujeto han de formarse a través del diálogo intersubjetivo, y ese diálogo tiene virtualidades epistémicas, pero la conciencia del sujeto como criterio último sigue siendo irrebasable (Cortina, 1993, 137 y ss.).

\section{Bibliografía}

AlEXANDER, R., "The evolution of social behavior», Annual Review of Ecology and Systematics, 5 (1974), 325-384.

Amor, J. R., Bioética y Neurociencias, Institut Borja de Bioètica/Universitat Ramon Llull, Barcelona, 2015.

Arana, J., La conciencia inexplicada, Biblioteca Nueva, Madrid, 2015.

Aranguren, J. L., «Prólogo», Adela Cortina, Ética mínima, Tecnos, Madrid, 1986, 5-14.

Aranguren, J. L., Ética, en Obras Completas, Trotta, Madrid, II, 1994, 159-502.

AUdi, R. La percepción moral, Avarigani, 2015.

Ayala, F. J. (2006), «Las raíces biológicas de la moralidad», en La evolución de un evolucionista, Universitat de València, 351-369.

Bergson, H., Las dos fuentes de la moral y de la religión, Tecnos, Madrid, 1996.

Boenm, C., Moral origins.The Evolution of Virtue, Altruism and Shame, New York, Basic Books, 2012.

Bonete, E. (2010), Neuroética práctica, Desclée de Brouwer, Bilbao, 2010.

Cela, C. J. y Ayala, F. J. (2001), Senderos de la evolución humana, Alianza, Madrid.

Conill, J., El enigma del animal fantástico, Tecnos, 1991.

Conill, J., " "La voz de la conciencia”. La conexión noológica de moralidad y religiosidad en Zubiri», Isegoría, 40 (2009), 115-134.

Conill, J., Ética hermenéutica, Tecnos, Madrid, 2006.

Cortina, A., Ética aplicada y democracia radical, Tecnos, Madrid, 1993.

Cortina, A., Neuroética y neuropolítica, Tecnos, Madrid, 2011 a.

Cortina, A., «Neuroética: ¿ética fundamental o ética aplicada?», en Diálogo filosófico, $\mathrm{n}^{\circ}$ 80, 205-224, 2011b.

Cortina, A. (coord.), Guía Comares de Neurofilosofía práctica, Comares, Granada, 2012.

Churchland, P., Braintrust, Princeton University Press, Princeton, 2011.

Champagne, F. and Curley, J., "How social experiences influence the brain», Current Opinion in Neurobiology 15 (2005), 704-709.

DARWIN, Ch., El origen del hombre, Crítica, Barcelona, 2009.

DE WAAL, F., «The chimpanzee's sense of social regularity and its relation to the human sense of justice», en Masters, R. \& Gruter, M. (eds.), The sense of justice: biological foundations of law, Sage Publications, Newbury Park, C.A., 1992, 241-255.

De WaAl, F., Primates and Philosophers, Princeton University Press, Princeton, N.J., 2006.

De Waal, F. Patricia S. Churchland, Telmo Pievani \& Estefano Parmigiani (ed.), Evolved Morality. The Biology and Philosophy of Human Conscience, Brill, Leiden, Boston, 2014. 
Evers, K. (2015), «Can We Be Epigenetically Proactive», en T. Metzinger \& J.M. Windt (eds.), Open Mind: 13 (T), Frankfurt a.M., 1-21.

GarcíA-MARZÁ, D., «Desobediencia civil», en Adela Cortina (dir.), Diez palabras clave en Filosofía Política, Verbo Divino, Estella, 1998, 97-125.

Habermas, J. (1985), Conciencia moral y acción comunicativa, Península, Barcelona.

Habermas, J. (2006), Entre naturalismo y religión, Paidós, Barcelona.

Habermas, J. (2009), Philosophische Texte, Bd. 5, Suhrkamp, Frankfurt.

Haidt, J. The Righteous Mind: Why Good People are Divided by Politics and Religion, Pantheon Books, 2012.

HAynES, J. D., «Brain Reading: decoding mental states from brain activity in humans», Illes, Judy \& Sahakian, Barbara J. (ed.), 2011, 3-13.

HeubüLt, W., «Gewissen bei Kant», Kant Studien, 71, 1 - 4 (1980), 445-454.

HiLl, T. Jr., "Four Conceptions of Conscience», en Ian Shapiro and Robert Adams, Integrity and Conscience, New York University Press, 1998, 13-52.

Hume, D., Tratado de la naturaleza humana, II, Editora Nacional, Madrid, 1977.

Iilles, J. and SaHaKian, B. (eds.), The Oxford Handbook of Neuroethics, Oxford University Press, 2011.

JAcoboni, M., Las neuronas espejo, Katz, Barcelona, 2009.

INSEL, T. and RusSEL, F. (2004), «How the brain processes social information: Searching for the social brain», Annual Review of Neuroscience 27, 697-722.

Joyce, R. (2014), «The origins of moral judgement», en Frans. M. de Waal, Patricia S. Churchland, Telmo Pievani \& Estefano Parmigiani, 2014, 261-278.

Kant, I., Lecciones de Ética, Crítica, Barcelona, 1988.

Kant, I., La Metafísica de las Costumbres, Tecnos, Madrid, 1989.

Kant, I., La Religión dentro de los Límites de la mera Razón, Alianza, Madrid, 1969.

Kant, I., Crítica de la Razón práctica, Alianza, Madrid, 2000.

Kitcher, P., «Is a naturalized ethics possible?», en Frans. M. de Waal, Patricia S. Churchland, Telmo Pievani \& Estefano Parmigiani, (ed.), 2014, 245-260.

KLEIN, C., "Images are not the Evidence in Neuroimaging», in British Journal for the Philosophy of Science, 61 (2) (2010), 265-278.

KorsgaAard, CH., The Sources of Normativity, Cambridge University Press, 1996.

Lavazza, A. \& de Caro, M., «Not so Fast. On Some Bold Neuroscientific Claims Concerning Human Agency», Neuroethics, $n^{\circ} 3$ (2010), 23-41.

Levy, N. (2007), Neuroethics, Cambridge University Press, New York.

Marcus, S. (2002), Neuroethics: Mapping The Field. Conference Proceedings, The Dana Press, New York.

Moll, J., de Oliveira-Souza, R. et alii, «The Neural Correlates of Moral Sensitivity: A Functional Magnetic Resonance Imaging Investigation of Basic and Moral Emotions», The Journal of Neuroscience, 22 (7) (2002), 2730-2736.

Moll, J., Zahn, R., DE Oliveira-SouZA, R. et alii (2005), «The neural basis of human moral cognition», Nat Rev Neuroscience, 6 (2005), 799-809.

Morgado, I., Cómo percibimos el mundo, Ariel, Barcelona, 2012.

Nietzsche, F., Die fröhliche Wissenschaft, en Kritische Studien Ausgabe. Herausgegeben von Giorgio Colli und Mazzino Montinari, Bd. III, De Gruyter, Berlin, 1999.

Nuccetelli, S. and Shea, G. (eds.), Ethical Naturalism: Current Debates, Cambridge Univ. Pres, 2012.

OJakangas, M., The Voice of Conscience. A Political Genealogy of Western Ethical Experience, Bloomsbury, New York, 2013. 
Ortega, C., «¿Naturalizar la idea de justicia? Una respuesta crítica desde la teoría moral de Jürgen Habermas», en este mismo volumen de Pensamiento.

Pallarés, D., «Críticas y orientaciones para el estudio en neuroética», en Recerca, 2013, 85-102.

POLDRACK, R., «Can cognitive processes be inferred from neuroimaging data?», Trends in Cognitive Sciences, 10/2, (2006), 59-63.

Rawls, J., Teoría de la Justicia, F.C.E., México, Madrid, Buenos Aires, 1979.

Rawls, J., Liberalismo político, Crítica, Barcelona, 1996.

- Recerca, no 13 (2013), «Retos actuales de la Neuroética. Current Challenges for Neuroethics».

RichART, A., «El origen evolutivo de la agencia moral y sus implicaciones para la ética» en este mismo volumen de Pensamiento.

Roskies, A., (2002): "Neuroethics for the new millenium», Neuron, 35, 21-23; Walter Glannon (ed.) (2007), 12-18.

Salles, A. y Evers, K. (coords.), La vida social del cerebro, Fontamara, México, 2014.

Suhler, C. and Churchland, P., "The neurological basis of morality», en Illes, Judy and Sahakian, Barbara J. (eds.), The Oxford Handbook of Neuroethics, 2011, 33-58.

TRIVERS, R. L., «The evolution of reciprocal altruism» Q. Rev. Biol, 46 (1971), 35-57.

Universidad de Valencia

Adela Cortina

AdelaCortina@uv.es

[Artículo aprobado para publicación en octubre de 2016] 